\title{
Academic writing practices among Master's Degree students in the Nepalese universities
}

\author{
Banshidhar Joshi \\ MPhil Scholar, Graduate School of Education, Tribhuvan University
}

\begin{abstract}
This study explored the academic writing practices in the Nepalese universities and difficulties teachers and students come across in the multilingual context of Nepal. As my study is guided by interpretive paradigm, it demands phenomenological qualitative research design to explore the multiple realities through interviews, documents analysis and focus group discussion. For this, I chose Far Western University, Mid-Western University and Tribhuwan University central campuses as my research site. Two students and two teachers from each of these universities as the study participants were selected with the help of purposive sampling strategy. The participants were interviewed and involved in the focus group discussions and their written documents were analyzed. Thesis writing, translation, book reviews, term paper writing and essay writing were found practised in the universities. Lack of teachers' own academic writing practices and creation, lack of involvement in professional development activities, lack of much practice in academic paper in classes, lack of motivation and feedback to students in writing, students' avoidance of writing and poor performance from very beginning, lack of appropriate pedagogy and indifference to academic writing practices and professional development from university administration are the causes of poor performance in academic writing practices in the universities.
\end{abstract}

Keywords: academic writing, thesis, pedagogy, Master's degree, writing practices

\section{Introduction}

Scholars may be native speakers of English or non-native speakers. However, they are required to use English language and the format of academic writing in their learning course or profession. Academicians are found involved in writing books, essays, conference papers, academic journal articles, dissertation or thesis, research papers, translation, literary analysis, abstract and explication in which academic writing is used. Students, professors, and researchers in every discipline are using academic writing to convey ideas, make arguments and engage in scholarly 
conversation. Academic writing is characterized by evidence - based on arguments, precise word choice, logical organization, and an impersonal tone. In this regards Strongman (2013) says writing is about communicating with words and academic writing is about choosing words carefully to communicate complex ideas to a range of readers and audiences. In the age of neo-colonialism, neo-liberalism and globalization, English language has become a dominant language and there is much influence of English language in academic writing. Whether English is taught as a foreign language or a second language, most of the e-books or printed books or other academic documents are in English. These books and documents are functioning as guiding principles and formats for others.

In the multilingual context of Nepal, the scholars as well as students are also seen following the formats, structure and content of native speakers of English in academic papers.In developing academic writing, they need to contextualize the content of the writing and need to apply multilingual pedagogy like translanguaging in developing writing skill in multilingual students and they wouldn't have developed the feeling of fear to be involved in academic writing activities. As Canagarajah (2012) says, writing is not just constitutive, it is also performative. We don't write only to construct a rule-governed text. Although it is important for texts to be constructed sensibly in order to be meaningful, we write in order to perform important social acts. We write to achieve specific interests, represent our preferred values and identities, and fulfill diverse needs.

As I have experience of teaching from school level to college level students, most of the school and college level students are not solving composition questions in their answer sheets and their writing is not satisfactory too. Although writing skill is a mustfor transmission and transformation of knowledge, in teaching language, writing skill is not much emphasized by the teachers and students as Sapkota (2012) says among the different language skills, the students feel writing skill to be the most difficult in real practice and in the examination. It is mostly assigned as homework in teaching learning activities and the answer made by the teacher is supposed to be final and correct.

In the higher level of education, people are not taking much interest in academic writing though there is a provision of academic writing. In practice, only a few people are found to be involved in the academic writing activities. As I myself have experience of being a student of MPhil leading to $\mathrm{PhD}$ programme at Tribhuwan University, only a few professors were found publishing their articles 
in the national and international research journals. This fact becomes clear when we were shown and given foreign researchers' research articles, model academic research proposals, interview extracts and review papers while teaching us in the MPhil classes. If they had published, they would have shown us in the classes. Some professors never talked about their own creations in the classes. Same thing happens in terms of book writing, we were not recommended any Nepali scholars' books in the classes. Behind this low performance at school as well as upper level of education in terms of academic writing, there might be some loopholes; either it might be individual interests or problems of students or lack of multilingual pedagogy or institutional problems in multilingual context of Nepal. Adas and Bakir (2013) view that unless the teacher is able to create an interest in the mind of the learners, $\mathrm{s} / \mathrm{he}$ can't expect the desired results. This shows it is a must to develop writing skill.

Kareem (2015), as cited in Ariyanti (2017), mentions that writing a good English composition seems never very easy. It requires an ability of assessing a good grammar, imagination and thought, exploring major and supporting ideas, putting them together revising, and then final editing.

From above mentioned things, writing is a must in school as well as in higher level classes, but the condition of academic writing practices in school level and higher level is not seen satisfactory that is clear from the academic practices in the universities of Nepal. To explore the weaknesses and unsatisfactory situation of academic writing and to find the way to improve the condition, it is necessary to conduct research.

There is need of sufficient study in academic writing to address the difficulties faced by students in developing language skills in general and academic writing skills in specific. Grabe and Kaplan (1996) view that students in English as a foreign language contexts will need English writing skills ranging from a simple paragraph and summary skills to the ability to write essays and professional articles. Thus, writing skill is not only important to the students of English education, but it is equally important for other students from different disciplines for their higher studies since English is used as a foreign language and language of academia. Otherwise, it will have bad effects on our students' learning and can hinder in getting higher education too. Therefore, this study can be a building block to address academic writing practices in schools and universities and it will also give insights to the academicians as well as other stakeholders of education. 
As a researcher, I wanted to explore academic practices among Nepali multilingual students of Nepal at bachelor's level and master's level students in terms of academic writing practices. In this scenario, this study explored the academic practices of the students and the methods teachers apply in the classroom, pedagogy they apply and the ways of improving the condition of academic writing practices of students. To fulfill these objectives, I tried to seek the answers of the following research questions:

1. What academic practices are practised and what methods do teachers apply in developing academic writing skills at the master's level in Nepalese universities?

2. What academic challenges do students come across in academic writing?

3. How do the teachers motivate students and what strategies do students employ in learning academic writing skills?

\section{Literature Review and Theoretical Framework}

Many researchers have conducted research in terms of different aspects of language teaching like effective grammar teaching methods, reading materials, vocabulary learning strategies, role and status of English, journal writing and its effectiveness, paragraph writing and teaching paragraph. To link and make this study systematic with the existing knowledge, I went through the following research work conducted by different scholars.

Adas and Bakir's (2013) study showed that blended learning was effective in improving students' writing abilities in general; students' motivation to learn increases when they are given the same material in different ways using technology and simulation and constant exposure to the material solves many problems. Alfaki (2015) found that university students have various writing problems: language problems at the level of morphology and syntax; usage errors, and mechanical mistakes, that is, spelling, punctuation and capitalization, lack of several writing development skills, cognitive problems and graphomotor problems. Bajgain's (2019) research found that writing a paragraph on a given topic is the easiest when picture with clues are given. Average score of writing paragraph with the clues along with picture is more fruitful than providing picture only. Attempts of teacher with positive attitudes help learn target language effectively. Mohite's (2014) study found that the students lacked the understanding of the compositional aspect of the English writing and they did not view their English written text as a means of communication. Oyedele and Chikwature (2016) found that English language students have a myriad of writing skills in composition writing. These include mother tongue interference, 
inconsistent use of mother tongue, spellings amongst other various difficulties. Teaching methods used by teachers were also another contributory factor. Yadav's (2017) study found journal writing to be an effective technique to make students reflect on what they have learnt and enhance their writing skill as well.

From the above studies, it is clear that different scholars have conducted different research studies on different aspects of English language teaching. It also shows that there is rich literature in terms of English writing difficulties in the context of the world. However, there is need to explore the practices and challenges faced by the students and teachers of the Nepalese universities in terms of academic paper writing. This area of research is still unexplored. Considering this fact, I forwarded my research work to explore academic writing practices and difficulties in the context of Nepal.

This study is based on the Process Genre Approach for teaching writing skills (Badger \& White,2000), which recognizes that effective teaching methodology for writing needs to integrate the insights from the product, process and genre approaches. This integrated approach to language teaching aims at maximizing meaningful communication and classroom interaction in meaningful situation. It fosters holistic learning such as sharing of information, experiences and development of value. It gives language skills their most meaningful, practical and relevant application, while at the same time giving the students the necessary tools for full learning (Nyasimi, 2009). According to Badgar and White (2000), the development of writing in a process genre (integrated) approach, classroom learning takes place when teachers draw out the potential of the students as well as provide appropriate input to them. It is also noted that the development varies between different groups of students because they are at different states of their writing development, the teachers need to assess the needs of the students to determine the kind of input they need. There are three possible sources of input in the Process Genre Approach to teaching the writing skills: teachers, learners and samples of the target genre. Teachers provide them input in terms of instruction on language use and content, for instance, by asking students to think about why they are writing on a particular topic. An alternative to this can be a demonstration by the teachers. On the other hand, students can do the same in group discussion or observing other students' written text. Samples from the target genre can also be an important source of input about contextual and linguistic knowledge. This implies that there is need for teachers to adopt the integrated approach to teaching writing skills in order to enable students achieve communicative competence in writing. Integrated approach allows 
for collaborative learning among students as well as effective interaction between teachers and students in writing classrooms. By working in groups, learners interact freely and also develop their critical thinking. It also enables teachers to monitor students to progress at every writing stage to determine the kind of input needed, as well as using teaching and learning resources to illustrate the organization of a particular genre. Adopting the integrated approach to the teaching of academic writing skills will enhance effective learning leading to students' mastery of writing skills and achievement in academic writing.

\section{Methods and Procedures}

\section{Research Design}

My present study is guided by interpretive paradigm, which believes in multiple realities and believes that individuals have consciousness. This study is based on the qualitative research under which I selected phenomenology research design. Cresswell (2007) says that the type of problem best suited for phenomenology research design is one that is important to understand several individual's common or shared experiences of phenomenon. It would be important to understand these common experiences in order to develop practices or polices, or to develop a deeper understanding about the features of the phenomenon (p.60). My present study explored academic writing practices at masters' level students.

\section{Research Site and Study Sample}

The research site of study was Far Western University, Mid-Western University and Tribhuvan University central campuses of Nepal. I, as a researcher, selected central university campuses on the basis of proximity of the campuses to the researcher. Samples were selected on the basis of purposive sampling strategy. The subjects of this study were students studying and lecturers teaching in those universities. Two students and two teachers from each of these universities as the study participants were selected.

\section{Tools for Data Collection}

Creswell (2007) visualizes that often data collection in phenomenological studies consists of in-depth interviews and multiple interviews with participants. Other forms of data may also be collected, such as observations, journals, art, music, and other forms of art (p.61). To achieve the objectives of my study, I applied semi-structured interviews, informal interaction, document analysis, and participant observation as the research tools. 


\section{Ethical Consideration}

For ethical consideration, I followed anonymity, confidentiality and informed consent. As the researcher himself or herself is considered to be the research instrument, the plan of inquiry needs to be developed and altered as the study progresses. For this as a qualitative researcher, I considered all of the above mentioned ethical considerations while I conducted my research study as trustworthy and rigor play an important role which I valued much in my study.

\section{Results and Discussion}

In this section, the data were analyzed and discussed under the given themes.

\section{Academic Practices Focusing on Product, not on Process}

The responses of the participants showed that they were rarely involved in writing academic essays, book reviews, article reviews, thesis reviews, translation, term paper writing and case studies, but they were not well-informed and didn't get chance to be familiar with the process of writing before assigning them above topics. Teachers did not teach those elements and structure of the assigned academic writing topics. They were told to write term paper, book reviews and other academic writing even without informing language used in book reviews and term paper. One of the participants says:

In our classes our teachers not often assign us academic writing activities. We are often assigned such assignment activities for homework or during holidays, not in classrooms. We complete those papers in essay forms because we don't have any idea of structure of those academic activities and language used in the topics assigned. They say do this and do that and at the time of submission, they didn't say anything. Once I saw process of essay writing and types of essays in a school level English book, but we were not informed about them. The teachers didn't inform us how to write basic essays and haven't recommended an essay book to read in the classroom yet.

Gonye et al. (2012) mentions that students should view writing as different from speech and they should treat writing as a process rather than a product. In other words, it goes through different steps.

\section{Lack of Motivation in Writing}

The data shows that students are not serious and resourceful. Most of the students in class do not have interest in writing. They do the task when the teachers 
assign them tasks. Otherwise, they themselves do not try to be involved in writing. As one of the participants who teaches at the central university campus at the master's level says:

They have poor base even they feel uncomfortable in composing paragraph. They have poor performance from very beginning. If they were helped in simple writing in previous classes, they would do better. Next they aren't resourceful. They don't try to read articles, book reviews and translations done by others themselves. Being a resourceful student matters in academic writing, but their poor writing demotivates them in writing themselves.

Adas and Bakir (2013) mention that unless the teacher is able to create an interest in the minds of the learners, he can't expect the desired results. A good teacher teaches, a better teacher explains and the best teacher inspires.

\section{Lack of Teacher's Creativity and Sharing Cultures}

The data shows that teachers themselves do not involve themselves in academic writing and do not share their work to the students. In this regard one of the participants of M.Ed. fourth semester says:

Most of our teachers at our universities haven't written term papers, book reviews, and research articles themselves and haven't shared their own academic papers with us. If they had written any research articles or book reviews, they would have shared their experiences and research finding with us. Other things they share with us like sometimes they say that 6th batch students were creative, or she or he was good... I think they are only familiar with theoretical aspects of academic writing but not with practical aspect. If they shared their experiences by involving themselves in writing academic papers practically, they would make our classes more interesting, and they would give us feedback. Further, it would be motivating for us too.

In practice there should be sharing of ideas and experiences so that novice learners can get chance for learning as well as feedback from others and improve their writing. Graham, Mckeown, Kiuhara, \& Harris (2012) say that feedback, particularly from adults with writing expertise, has been shown to have a significant impact on student writing quality. Similarly, Tiwari (2019) in his study mentions that unsupportive behavior of supervisors and difficulties of selecting the appropriate field or area of the study are major challenges while writing the thesis in English education. 


\section{Lack of Publication and Conduction of Conferences}

This study also shows that there is no provision of publishing any research articles in the journals and presenting papers in the conferences at their own campuses. One of the participants who has recently completed master's degree says:

We could have tried to write and present the paper if there is such provision for it, but sometimes we attend the conferences conducted by Scholars Association of Nepal and NELTA. Scholars Association of Nepal has provided platform to share experiences and learn something from seniors. Similarly, if our campus published journals including the articles of our teachers and students, we would be motivated to write academic papers for those publications, but there is not such culture in our campuses.

Shafie, Maesin, Osman, Nayan and Mansor (2010) say first, writing usually suffers from lack of interaction, which stimulates oral production in conversation. This shows that there is need of interaction between or among the learners and the experts for developing academic writing skills.

\section{Turn Deaf Ears to Academic Writing Practices}

The research findings also show that the campus administration does not have any interests for scholarly activities. It was found that campus administration has ignored scholarly activities though some of the teachers were willing to conduct workshops, conferences and seminars at campus but the campus administration is reluctant to those activities. In terms of academic practices to be conducted at campus, one of the assistant professors and head of the English education department teaching at master's degree says:

As I am a senior teacher I talk to my colleagues to conduct scholarly activities at campus, but campus administration doesn't support for these activities. They say that there is lack of budget, but some of my colleagues who have joined MPhil and PhD programs, they are self-motivated to be involved in scholarly activities and they are eager to write research articles too. There will be positive change in the future in terms of academic writing. We publish campus anthology named Education Mirror every year which contains literary works such as poems, short stories, articles, especially a collection from various students and teachers. Similarly some students are writing news articles for local level newspapers and magazines. If we could collect their writing and create the environment for their presentation, it would bereally motivating, but 
we have no such culture in our universities. Administration turns a deaf ear to our demands.

Phothongsunan (2016) says that the support from the university can encourage the academics to be more involved and motivated to write the academic article and also it would be beneficial in their study. Similarly, Tiwari (2019) mentions that campus never organized research methodology, related workshop and seminars which are essential for students who are writing thesis.

\section{Lack of Multilingual Pedagogy}

The findings of this study also show that there is not multilingual pedagogy in academic writing practices in classroom. Since, 123 languages are spoken in Nepal as mother tongues, our country is a multilingual country. Multilingual writers or students writing English as their second or foreign language need some support as native English speakers: feedback on draft, opportunities to revise, tutoring, and examples of good writing activities. But these things rarely happen in the classroom. In response to multilingual pedagogy one of the participants says:

In our class English-only policy was in the past and still it is working at present. First it would be better to be competent in first language in terms of listening, speaking, reading and writing. Without developing these skills in the first language how it could be possible in the second or foreign language, i.e. English? Next I have never got any feedback on my draft, so I didn't need to revise. Furthermore, we are not being provided any sampleseither in L1 or L2 before writing any term paper; book reviews or any research proposals though most of academic papers are written in English.

Corbett (1971) mentions that in particular, student performance on writing tasks can be improved if writing instruction provides models to emulate. When teachers provide students with concrete examples of what successful work looks like, students are likely to perform better.

If the teacher is asked to teach the students whose English knowledge absolutely poor at the under graduate level, it becomes a challenge. Similarly, Mumin (2020) says academic writing is an essential skill for higher education and often used as a form of assessment. Academic writing is also very difficult to define due to its situated concept that varies from one academic context to another. This makes especially difficult for international students who may have limited academic writing experience and whose first language is not English. 


\section{Strategies to Improve the Situation}

The study showed varied responses regarding the strategies to improve the present situation of scholarly activities in the universities. The study showed that the learners need help from teachers in terms of feedback, in the use of multilingual pedagogy, in terms of feedback, teachers' experiences in terms of academic writing, authentic academic papers as samples, detailed information in terms of structure, process and language of academic articles. Similarly, teachers viewed that students have poor performance from very beginning, we need to be alert. In this regard, one of the associate professors and PhD scholar at TU teaching at bachelor's and master's level says:

First of all teachers and students should be serious. They need to think that they need to develop academic culture in the universities. Secondly, paper presentation and academic publishing should be the part of curriculum so that students can have practical knowledge. Third, students' reading of academic writing should be emphasized so that they can get exposure to academic writing styles. Fourthly, workshops should be conducted so that there can be sharing culture. And finally, there should be community of practice among the teachers. All teachers should be academicians rather than politicians. Politics in the universities is also destroying our academic culture in the universities. The policy needs to be strongly implemented by the concerned people and there should be no back support to those teachers who are not involved in academic activities. Teachers 'promotion criteria should be their involvement in academic activities. If any teacher is not involved in academic activities like conducting and participating in workshops, seminars, writing articles and publishing, they need to be penalized in the context of Nepal. In fact, teachers and professors are the most responsible people for developing academic writing skills in the students. It is because it is the teachers who are in direct contact with the students for their learning and doing academic activities. The bad trend in our country is that teachers take training only for training, not for implementing in the classroom. Actually it is a serious matter.

As Phothongsunan (2016) says, the university lecturers need encouragement and support to publishing their academic works as a means of securing professional development, enhancing research culture and maintaining and increasing the national and international reputation of the university along with quality assurance. 


\section{Challenges in Academic Writing and Curriculum}

The findings from focus group discussion, document analysis and from the interviews showed that at undergraduate and graduate levels, students have difficulties due to the lack of writing practices in previous classes. If they had practised basic writing like paragraph writing, essay writing and letter writing at school level well, they would feel comfortable, but the situation is not like that. The students who are from private schools, they did a little, but not satisfactorily in writing. Next, it was also found that students have not developed their writing skills on different aspects of academic writing as objectives mentioned in curriculum. In this regard, one of the teachers who teach at bachelor's and master's level students says:

Students often feel difficulty in generating ideas, sentence construction, organizing ideas, paragraphing, paraphrasing, referencing and grammar. Next, they are not autonomous and resourceful; they don't search for academic papers from different sources. They simply go through one or two books that we recommend them for reading and later on they copy the content of their recommended books or papers and submit to us as a completion of their assignment. Furthermore, there is lack of scholarly books and articles too in the universities. I don't think all my students have developed writing skills as prescribed in the curriculum. Its main cause is here most of the students learn for examinations just to pass, not to develop writing skills. People concerned do not seem serous in this issue. Students'learning is exam oriented rather than knowledge or skill oriented.

Elandar et al.(2006) say that essays and related written work provide opportunities for students to demonstrate some of the most demanding learning outcomes; however, students are often more confused about what constitutes a good essay than they are about the criteria for other types of assigned. Further Tardy (2010) mentions that often, in higher education, writing tasks requires students to draw on sources and adopt the styles and genres of academic discourse

\section{Conclusion}

The data collected through the multiple sources in this study indicate that there is provision of writing skill from very beginning classes. However, the students are not found developing academic writing skills as the objectives mentioned in the curriculum. Lack of motivation, lack of teachers' involvement in academic activities, 
lack of being resourceful from students' side, lack of easy access to materials, proper feedback and guidance in writing from very beginning, lack of appropriate pedagogy and unwillingness nature of university or campus administration for promoting scholarly activities were found responsible factors for unsatisfactory condition of academic practices in Nepalese universities.

From this study, it is recommended that writing practice should be focused from very beginning with process and structures of writing. The school and colleges should facilitate students for publishing and presenting their papers that can motivate students to be involved in academic writing. For developing scholarly activities, teachers should do scholarly activities first and present themselves with the help of their own creations as a model academic writer. Next, the leadership should be given to the scholars who have good experience of scholarly activities in the campuses and universities. Moreover, students are from different ethnic groups and they are learning in multilingual context. For this, there is need of multilingual pedagogy in classroom, which would help multilingual learners in their learning. Furthermore, the students need to be involved in peer reviews for their writing and there should be positive feedback individually from the teachers since the students are from different social class and they have different learning abilities. Finally, teachers should make their students conscious about plagiarism.

\section{References}

Adas, D. \& Bakir, A. (2013).Writing and new solutions: blended learning as an approach to improve writing abilities. International Journal of Humanities and Social Sciences, 3(9).

Ahmed, A. (2010). Contextual challenges to Egyptian students' writing development. International Journal of Arts and Sciences, 3(4), 503-522.

Alfaki, I. M. (2015).University students' English writing problems: diagnosis and remedy. International Journal of English Language Teaching, 3, 40-52.

Ariyanti, A. (2017). EFL students' needs in essay writing. Advances in Social Sciences, Education and Humanities Research (ASSEHR), 158,111-121.

Badgar, R. \& White, G. (2000).A process genre approach to teaching writing.ELT Journal,54, 153-160.

Bista, K. (2011). Teaching English as a foreign/second language in Nepal: Past and present. Online Submission, 11(32), 1-9.

Canagarajah, S. (2012). Toward a writing pedagogy of shuttling between languages: Learningfrom multilingual writers. College English, 68(6), 589-604. 
Corbett, E.P. (1971). The theory and practice of imitation in classical rhetoric. College Composition and Communication, 22,243-250.doi:10.23071356450 Creswell, J.W. (2007). Qualitative inquiry and research design. London: Sage Publications.

Dar, M.F., \&Khan, I. (2015).Writing anxiety among public and private sectors Pakistani undergraduate university students. Pakistan Journal of Gender Studies, 10(1),121-136.

Dawson, D.\& Yong, J. (2008).Structures and skills in English. Harare: Longman. Duwadi, E.P. (2018). Historical developments in teaching and learning of English in Nepal.(178-184) Retrieved from: https://www.researchgate.net/ publication/322952317

Elandar, J., Harrington, K., Norton, L., Robinson, H., \& Reddy, P. (2006). Complex skills and academic Writing: A Review of Evidence About the types of learning required to meet core assess me criteria. Assessment \& Evaluation in Higher Education.

Ferris, D. (1998). Teaching EFL composition: Purpose, process and practice. In T.L. Good\& J.E. Brophy (Eds.), Looking in classroom (6 $6^{\text {th }}$ edition). New York: Hameed.

Gonye, J., Mareva, R., Dudu, W.T. \& Sibanda (2012). Academic writing challenges at universities in Zimbabwe: A case study of great Zimbabwe University. Journal of English and Literature. 3 (3), 77 - 83.

Grabe, W. \& Kaplan, R. (1996).Theory and practice of writing. New York: Addison Wesley Longman.

Graham, S., Mckeown, D., Kiuhara, S., \&Harris, K. R. (2012).A meta-analysis of writing instructionfor students in elementary grades. Journal of Educational Psychology, 104, 879-896.

Horner, B., Lu, M., Royster, J.J., \& Trimber, J. (2011). Language differences in writing:

Towards a translingual approach. College English,73(3), 303-21.

Joyace, P. (2016). L2 vocabulary learning and testing: students' proficiency and the use of L1 translations versus L2 definitions. Journal of NELTA, 21 (1-2), 93104.

Mohite, M. (2014).An investigation into the English language writing strategies used by Polish EFL secondary school learners. London: London Metropolitan University. 
Mouri, S.S. (2016). English composition writing skills of class five students:

Teaching and learning practices at government schools in Dhaka. Dhaka: BRAC University.

Mumin, M. A. (2020). A narrative study of international postgraduate students' conceptualization of academic writing through assessment feedback in a UK university (Order No. 28200117). Available from ProQuest Dissertations \& Theses Global. (2440398921). Retrieved fromhttps://search.proquest. com/dissertations-theses/narrative-study-international-postgraduate/ docview $/ 2440398921 /$ se-2?accountid $=188747$

Nyangau, B. N. (2014). Challenges students face in learning essay writing skills in English language in secondary schools in Manga District, Nyamira County, Kenya. Kenyatta University.

Palys, T. (2008). Purposive sampling. In Given, L.M. (Ed), The Sage Encyclopedia of Qualitative research methods, 2, 697-698.

Phothongsunan, S. (2016). Thai University Academics' challenges of writing for publication in English. Theory and Practice in Language Studies, 6(4), 681 685.

Phyak, P. (2013).Language ideologies and local languages as the medium-ofinstruction Policy: a critical ethnography of a multilingual school in Nepal. England: Routledge.

Sapkota, A. (2012). Developing students' writing skill through peer and teacher correction. An action research. Journal of NELTA, 17 (1-2), 70-82.

Strongman, L. (2013). Academic writing. Cambridge: Cambridge Scholars Publisher. Tardy, C.M. (2010). Writing for the World: Wikipedia an Introduction to academic writing. English Teaching Forum, 1. 12 - 27.

Tangpermpoon, T. (2008).Integrated approaches to improve students' writing skills for English major students. ABAC Journal, 28, 1-9.

Tiwari, H.P. (2019). Writing thesis in English Education: Challenges faced by students. Vol,1. $45-52$.

Yadhav, G. (2017). Journal writing in the EFL classroom of Nepal. Journal of NELTA, 22 (1-2), 67-74. 